\title{
Pesquisa de marcadores de trombofilia em eventos trombóticos arteriais e venosos: registro de 6 anos de investigação
}

\author{
Research on thrombophilic factors in arterial and venous thrombotic \\ events: a 6-year investigation register
}

\section{Marcos Arêas Marques ${ }^{1}$, Paulo Roberto Mattos da Silveira ${ }^{2}$, Arno von Ristow ${ }^{3}$, Marcus Gress ${ }^{4}$, Alberto Vescovi ${ }^{4}$, Bernardo Massière ${ }^{4}$, José Mussa Cury Filho ${ }^{4}$}

\section{Resumo}

Contexto: Os autores apresentam uma análise epidemiológica sobre a investigação de marcadores de trombofilia em pacientes que apresentaram eventos trombóticos arteriais e/ou venosos acompanhados no Departamento de Angiologia e de Cirurgia Vascular do CENTERVASC no período de janeiro de 2001 a janeiro de 2007.

Objetivo: Avaliar a prevalência de marcadores de trombofilias congênitas ou adquiridas nos eventos trombóticos venosos e/ou arteriais.

Métodos: Entre janeiro de 2001 e janeiro de 2007, 224 pacientes com eventos trombóticos venosos e/ou arteriais foram submetidos a uma rotina de investigação quanto à presença ou não de marcadores de trombofilia, independentemente da idade e história familiar dos pacientes, topografia do evento e presença ou ausência de fatores trombogênicos extrínsecos.

Resultados: Foram detectados marcadores de trombofilia em 112 pacientes ( $50 \%$ dos casos). Nestes, observou-se de modo predominante a positividade para anticorpos antifosfolipídios, anticardiolipina e/ou anticoagulante lúpico (39 casos), bem como a presença do fator $\mathrm{V}$ de Leiden (43 casos). O sistema venoso foi significativamente o mais acometido, e a ocorrência associada com condições trombogênicas extrínsecas esteve presente em 56 (50\%) dos portadores de marcadores de trombofilias.

Conclusões: A presença de marcadores de trombofilia nos pacientes com eventos trombóticos, venosos e/ou arteriais, independentemente da faixa etária ou da existência de fatores extrínsecos associados, foi significativa.

Palavras-chave: Trombofilia, tromboembolismo, fatores de risco.

\section{Introdução}

\section{Trombofilias hereditárias}

A diminuição dos níveis plasmáticos da antitrombina (AT) foi a primeira deficiência genética de anticoagulante natural associada à trombose venosa profunda

\begin{abstract}
Background: The authors report an epidemiological analysis of the investigation on thrombophilic factors in patients presenting with arterial and/or venous thrombotic events followed at the Angiology and Vascular Surgery Department at CENTERVASC, from January 2001 to January 2007.
\end{abstract}

Objective: To assess the prevalence of congenital or acquired thrombophilic markers in venous and/or arterial thrombotic events.

Methods: From January 2001 to January 2007, 224 patients with venous and/or arterial thrombotic events were screened for the presence of congenital or acquired thrombophilic markers independently of age and family history, location of thrombus and presence or absence of other thrombogenic factors.

Results: Thrombophilic factors were present in 112 patients $(50 \%$ of the cases), in whom predominant positive results for antiphospholipid, anticardiolipin and/or lupus anticoagulant antibodies (39 cases) as well as the presence of factor V Leiden (43 cases) were observed. The venous system was the most significantly affected, and other associated thrombogenic factors were present in $56(50 \%)$ carriers of genetic thrombophilic factors.

Conclusion: The presence of genetic thrombophilic factors in patients with venous and/or arterial thrombotic events, independently of age or presence of other associated factors, was significant.

Keywords: Thrombophilia, thromboembolism, risk factors.

(TVP). Descrita por Egeberg em $1965^{1}$, a AT, o principal cofator da heparina, é uma importante enzima inibidora de protease que ajuda a regular a função de diversas proteínas da cascata de coagulação. Sua principal função é a de produzir uma inibição fisiológica da trombina (fator IIa) e do

1. Chefe, Departamento de Angiologia, Centro Integrado de Prevenção, Diagnóstico e Tratamento Vascular (CENTERVASC), Rio de Janeiro, RJ. Professor colaborador, Universidade do Grande Rio Professor José de Souza Herdy (UNIGRANRIO), Duque de Caxias, RJ. Membro, Conselho Científico, SBACV.

2. Doutor, Medicina, Universidade Federal de São Paulo - Escola Paulista de Medicina (UNIFESP-EPM), São Paulo, SP. Professor associado, Pós-Graduação em Cirurgia Vascular e Endovascular, Pontifícia Universidade Católica do Rio de Janeiro (PUCRJ), Rio de Janeiro, RJ.

3. Diretor médico, CENTERVASC, Rio de Janeiro, RJ. Professor associado, Pós-Graduação em Cirurgia Vascular e Endovascular, PUCRJ, Rio de Janeiro, RJ.

4. Cirurgião vascular, CENTERVASC, Rio de Janeiro, RJ.

Não foram declarados conflitos de interesse associados à publicação deste artigo.

Artigo submetido em 25.03.08, aceito em 22.07.09.

J Vasc Bras. 2009;8(3):225-231.

Copyright $($ C 2009 by Sociedade Brasileira de Angiologia e de Cirurgia Vascular 
fator Xa, mas também atua na inibição dos fatores IX, XI e XII ativados e da calicreína e plasmina².Em 1981, Griffin et al. relataram pela primeira vez que a deficiência da proteína $\mathrm{C}(\mathrm{PC})$ em humanos provocava um estado de hipercoagulabilidade $^{3}$. A PC é uma proteína vitamina $\mathrm{K}$ dependente que atua na cascata de coagulação, basicamente inativando os cofatores V e VIII ativados, o que resulta em uma inibição natural da formação de trombina, justificando que a sua deficiência possa levar a um estado prótrombótico. Uma peculiaridade é a chamada necrose cutânea induzida por varfarina, a qual ocorre nos indivíduos portadores de deficiência de PC que iniciam o uso de antagonistas da vitamina $\mathrm{K}$ sem a concomitância da heparina ${ }^{3}$. Este fenômeno é consequência da queda dos níveis de PC plasmática antes da redução dos fatores de coagulação vitamina $\mathrm{K}$ dependentes (fatores VII, IX, X e II), levando a um estado de hipercoagulabilidade momentâneo. Nessa situação, há trombose microvascular da derme, o que pode provocar ulcerações disseminadas na pele (Figura 1).

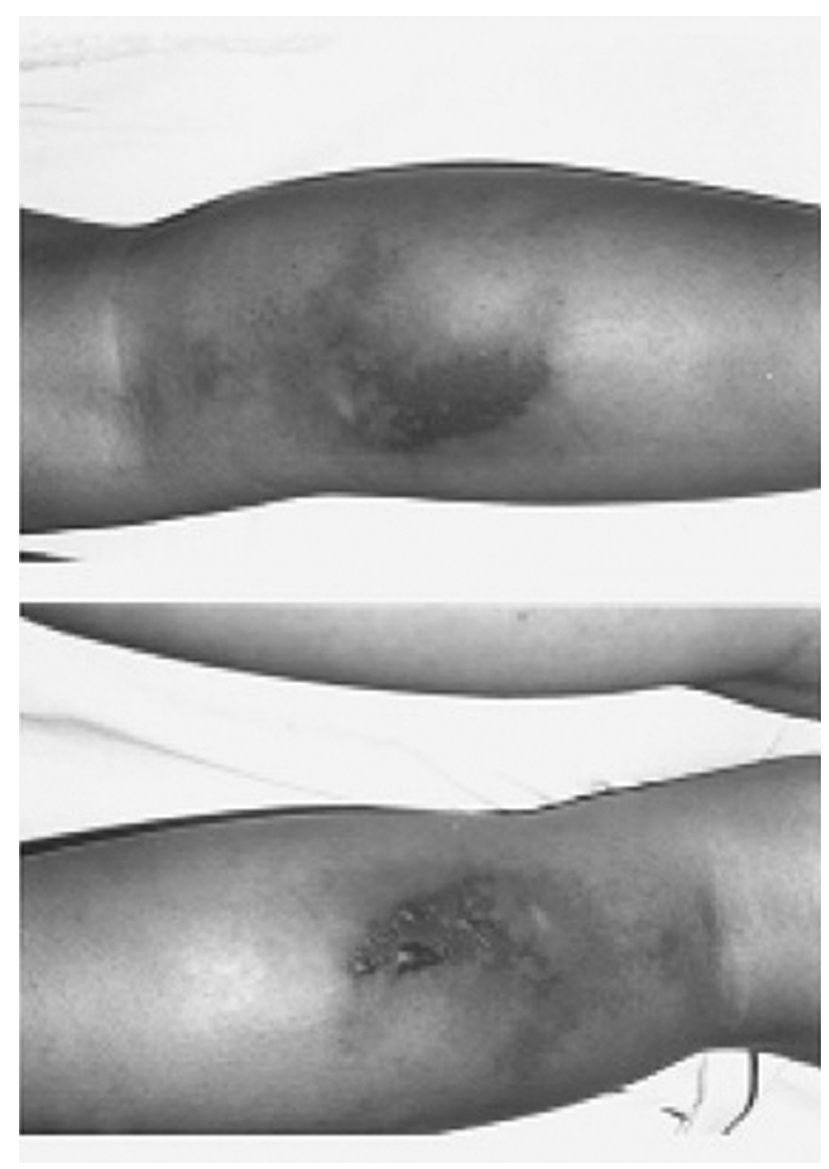

Figura 1 - Necrose cutânea induzida por varfarina em paciente portadora de deficiência de proteína $\mathrm{C}$
A deficiência homozigótica da PC é rara (um em cada 500.000-750.000 nascimentos $)^{3}$ e pode levar a um quadro conhecido como púrpura fulminans neonatal.A associação entre a deficiência hereditária da proteína S (PS) e evento tromboembólico foi identificada pela primeira vez em $1984^{4}$. A função da PS é servir como cofator enzimático da PC ativada na degradação proteolítica dos cofatores $\mathrm{V}$ e VIII ativados ${ }^{5}$. A deficiência homozigótica da PS é rara e, assim como na deficiência da PC, também pode levar ao quadro de púrpura fulminans neonatal.

Em 1993, Dahlback et al. descreveram uma nova e frequente trombofilia chamada de resistência hereditária à proteína C ativada (RPCA) ${ }^{6}$. A RPCA é, em 95\% dos casos, decorrente de um defeito genético específico, a mutação G-A no nucleotídeo 1691 do gene do cofator V da coagulação. Esta alteração é resultado da substituição da arginina $(\mathrm{R})$ por glutamina $(\mathrm{Q})$ na posição 506 da proteína, gerando um cofator $\mathrm{V}$ mutante chamado fator $\mathrm{V}$ de Leiden (FVL), a causa mais comum de trombofilia hereditária ${ }^{6}$. Descrita em 1996 por Poort et al. ${ }^{7}$, a mutação do gene da protrombina se originou provavelmente há $24.000 \mathrm{anos}^{8}$, quando houve uma transição $G$ para $A$ no nucleotídeo 20210 na região não traduzida, a 3' do gene da protrombina (fator II da coagulação). Com a descoberta dessas duas mutações (FVL e FIIG20210A), houve um significante aumento na comprovação do diagnóstico etiológico dos eventos de tromboembolismo ${ }^{9}$ e um estímulo para determinar uma padronização na investigação da etiopatogenia dos referidos episódios.

Estudos sugerem que a elevação dos níveis plasmáticos da homocisteína pode ser um fator de risco modificável para as doenças cardiovasculares e fenômenos tromboembólicos por sua possível ação lesiva sobre o endotélio ${ }^{10}$.

A hiper-homocisteinemia pode ser causada por deficiências enzimáticas genéticas associadas ou não às desordens nutricionais. As elevações leves e moderadas da homocisteína (níveis séricos entre 15 e $100 \mu \mathrm{M} / \mathrm{L}$ ) usualmente são encontradas em indivíduos normais portadores de deficiência heterozigótica das enzimas cistationina $\beta$-sintetase ou metileno tetrahidrofolato redutase, que podem estar prevalentes em até $1,5 \%$ da população ${ }^{11}$.

\section{Trombofilias adquiridas}

Diversas situações clínicas podem estar associadas à deficiência de AT, PC e OS, tanto por deficiência de sua 
síntese quanto por perda ou consumo excessivo. Dentre essas condições, encontram-se: hepatopatia, desnutrição, terapia com heparina, uso de antagonistas da vitamina $\mathrm{K}$, síndrome nefrótica, prematuridade, queimaduras extensas, doença intestinal inflamatória, microangiopatia trombótica, neoplasias, coagulação intravascular disseminada, sepse, gestação, quimioterapia e eventos trombóticos recentes $^{2-5}$.

A síndrome do anticorpo antifosfolipídio (SAF) é uma desordem sistêmica autoimune, caracterizada pela ocorrência de trombose arterial e/ou venosa, morte fetal e abortos espontâneos recorrentes, acompanhada de títulos elevados de anticorpos antifosfolipídios, sobretudo anticoagulante lúpico, anticorpo anticardiolipina (IgM e $\operatorname{IgG}$ ) e anticorpo anti- $\beta 2$-glicoproteína I (IgM e IgG) $)^{12}$.

A hiper-homocisteinemia é comumente encontrada nos pacientes com deficiência nutricional de piridoxina (vitamina B6), cianocobalamina (vitamina B12) e ácido fólico. Outras condições que podem levar a um aumento plasmático da homocisteína são: insuficiência renal crônica, hipotireoidismo, doença intestinal inflamatória, artrite reumatoide, transplante de órgãos e uso de drogas (anticonvulsivantes, L-Dopa, metotrexate, trimetropin, óxido nitroso e ciclosporina A). A hiper-homocisteinemia também pode ser adquirida por alguns hábitos de vida como tabagismo, consumo excessivo de café ou chá e vegetarianismo estrito. A idade é outro fator determinante devido ao déficit de absorção de vitamina B12 causado pela presença de gastrite atrófica em idosos.

\section{Critérios para investigação}

É importante levar em consideração o sistema vascular (venoso e/ou arterial) onde ocorre o evento trombótico, uma vez que isso implica em mecanismos fisiopatológicos distintos, com prognóstico e tratamentos também diferenciados. Em 2005, o Consenso Internacional de Trombofilia e Tromboembolismo Venoso ${ }^{13}$ sugeriu que a investigação de trombofilia deveria ser realizada nas seguintes situações:

a) em todos pacientes com o primeiro episódio de tromboembolismo espontâneo;

b) episódio de tromboembolismo antes dos 50 anos mesmo com fator de risco transitório; c) tromboembolismo secundário à gestação, ao uso de contraceptivos orais ou à terapia de reposição hormonal;

d) tromboembolismo recorrente, independente de outros fatores de risco;

e) tromboflebite superficial recorrente, na ausência de neoplasia ou veias varicosas;

f) tromboembolismo em localização não usual, como em seio venoso cerebral, veias hepática e mesentéricas e veia central de retina, antes dos 50 anos;

g) necrose cutânea induzida por varfarina e púrpura fulminante neonatal não relacionada a sepse;

h) parentes de primeiro grau assintomáticos de portadores sintomáticos de trombofilia, especialmente em mulheres em idade fértil;

i) dois abortos consecutivos ou três não consecutivos em qualquer idade gestacional, ou morte fetal após 20 semanas de gestação;

j) pré-eclâmpsia severa;

1) tromboembolismo em crianças.

A princípio, a investigação laboratorial deve ser realizada em todas as situações acima definidas que possam levar à suspeição de trombofilia, utilizando-se, para isso, a quantificação funcional dos inibidores da coagulação (AT, PC, PS), a quantificação da homocisteína plasmática, as pesquisas das mutações (FVL e FIIG20210A) e a determinação da presença de anticorpos antifosfolipídios (anticoagulante lúpico, anticardiolipina $\operatorname{IgM~e~} \operatorname{IgG})$.

Existem aspectos relevantes que devem ser levados em consideração, sempre que for possível, para que seja realizada uma investigação etiológica de trombofilia de forma mais sistemática:

a) o indivíduo diagnosticado como trombofílico deve, obrigatoriamente, ser submetido à profilaxia da trombose quando em situações de risco;

b) a presença de associações de defeitos trombofílicos implica em maior potencial trombogênico, exigindo maior vigilância sobre o seu portador;

c) a demonstração da presença ou ausência de anticorpos antifosfolipídios orienta quanto ao tempo e a intensidade da anticoagulação no paciente que apresenta um evento tromboembólico; 
d) a identificação de um defeito trombofílico congênito justifica a extensão da pesquisa à família a fim de encontrar portadores assintomáticos, os quais deverão receber orientação adequada em situações de risco.

\section{Métodos}

Este estudo envolveu o período compreendido entre janeiro de 2001 e janeiro de 2007, sendo investigados, quanto à presença de marcadores de trombofilia, 224 pacientes (130 mulheres e 94 homens) que apresentaram eventos trombóticos venosos e/ou arteriais independente da topografia. A rotina investigativa incluiu a pesquisa do FVL e da FIIG20210A pelo método de reação em cadeia da polimerase (PCR) em qualquer momento do evento trombótico e independente do uso ou não de anticoagulantes.

A pesquisa da deficiência da AT foi realizada pelo método colorimétrico com substrato cromogênico sintético para AT funcional, e a das deficiências da PC e PS, pelo método colorimétrico com substrato cromogênico sintético para PC e PS funcionais. As dosagens de AT, PC e PS foram realizadas sempre pelo menos 30 dias após o término da anticoagulação oral com varfarina sódica.

Os anticorpos anticardiolipina $\operatorname{IgM}$ e $\operatorname{IgG}$ foram investigados pelo método ELISA, de acordo com a normatização da declaração de consenso internacional de atualização do critério de definição da SAF publicado em $2006^{14}$.

A presença do anticoagulante lúpico foi detectada pelo prolongamento de um dos seguintes testes: tempo de tromboplastina parcial ativado, veneno de víbora de Russel diluído e tempo de inibição da tromboplastina.

A dosagem de homocisteína sérica foi realizada após um jejum de 12 horas pelo método HPLC (cromatografia líquida de alta performance).

Com exceção da pesquisa do FVL e da FIIG20210A, todos os testes alterados foram repetidos para confirmação.

Todos os eventos trombóticos foram confirmados por exames complementares de imagem (eco-Doppler colorido, angiorressonância magnética ou angiotomografia computadorizada).

\section{Resultados}

Dos 224 pacientes investigados, $112(50 \%)$ tiveram na pesquisa laboratorial resultados positivos para marcadores de trombofilia, constituindo-se em objeto de análise para este trabalho. Dos 112 pacientes portadores de marcadores de trombofilia, $61(54,46 \%)$ eram do sexo feminino e 51 $(45,54 \%)$ do sexo masculino, com uma média de idade de 48,11 anos (16-81 anos). Noventa e sete $(86,6 \%)$ dos eventos trombóticos ocorreram no sistema venoso e $14(12,5 \%)$ no sistema arterial. Apenas em um único caso $(0,9 \%)$ houve o comprometimento associado em ambos os sistemas.

Nos 97 eventos trombóticos venosos, 90 (92,78\%) ocorreram nos membros inferiores, sendo raras as manifestações em outros locais (Figura 2), enquanto que nos 14 eventos arteriais, seis $(42,86 \%)$ tiveram outras localizações (carótidas, membros superiores, sistema nervoso central, retina).

Fatores trombogênicos extrínsecos associados estavam presentes em 56 pacientes (50\%), representados por cirurgia (17 casos), doenças autoimunes (nove casos), imobilização prolongada (oito casos), uso de estrogênios (oito casos), puerpério (dois casos), neoplasia (três casos)

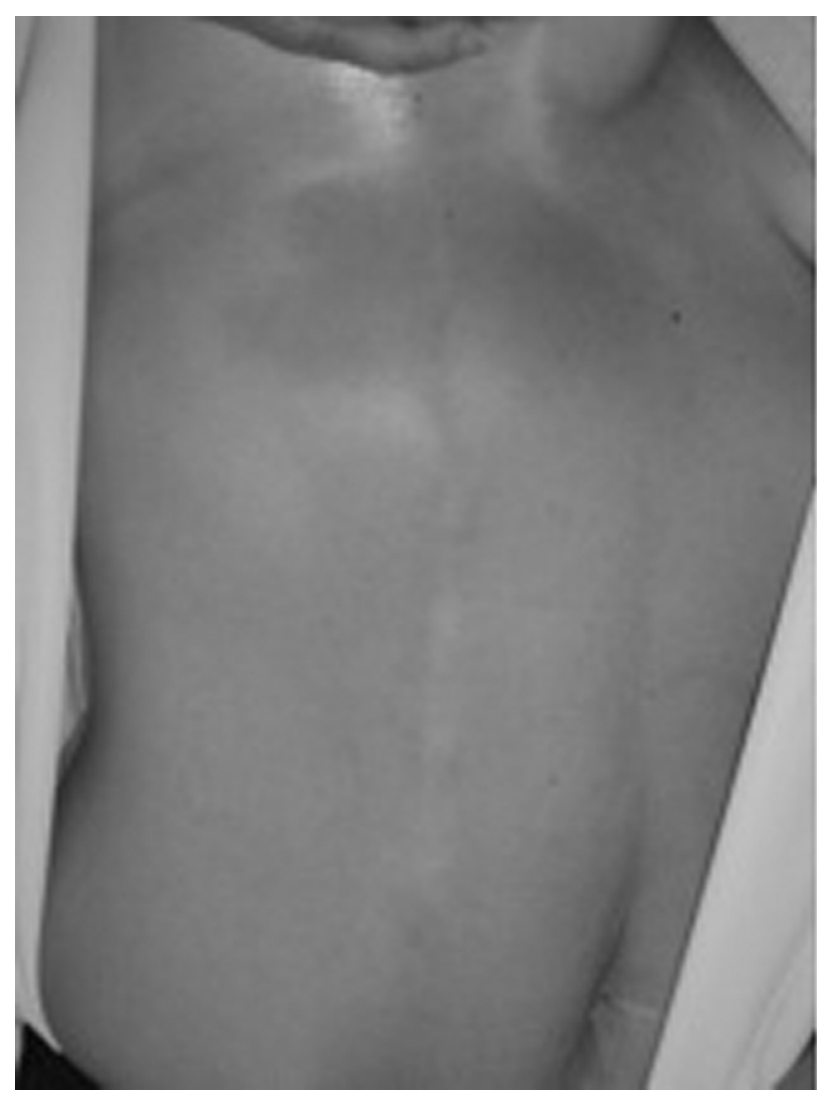

Figura 2 - Caso de trombose venosa em sítio não usual; tromboflebite de Mondor associada à síndrome do anticorpo antifosfolipídio 
e outros fatores de risco (seis casos - alcoolismo, trombocitose, hipertensão arterial sistêmica e tabagismo). Em três pacientes, observou-se associação de dois fatores de risco. Os 56 pacientes restantes do subgrupo (50\%) manifestaram a trombose sem um fator predisponente identificável clinicamente, respondendo pela chamada "trombose espontânea".

A incidência dos marcadores de trombofilia nos 112 casos está expressa na Tabela 1, sendo diagnosticada em 101 pacientes $(90,18 \%)$ de forma isolada e em 11 pacientes $(9,82 \%)$ em associação. Quanto à relação entre o tipo de marcador de trombofilia e a localização do evento trombótico (venoso, arterial ou misto), observou-se que, no sistema venoso, o FVL e a SAF (com predomínio do anticorpo anticardiolipina) estiveram presentes em 71 eventos $(65,74 \%)$ de tromboembolismo atribuídos à existência de trombofilia (Figura 3). Já no sistema arterial, a presença do

Tabela 1 - Prevalência das 123 alterações trombofílicas em 112 pacientes

\begin{tabular}{lc}
\hline Alteração trombofílica & $\mathrm{N}^{\mathrm{o}}$ de casos \\
\hline Deficiência de antitrombina III & 2 \\
Deficiência de proteína C & 3 \\
Deficiência de proteína S & 4 \\
Fator V de Leiden & 43 \\
Mutação da protrombina G20210A & 20 \\
Hiper-homocisteinemia & 12 \\
Anticorpo anticardiolipina e/ou & 39 \\
anticoagulante lúpico & \\
\hline
\end{tabular}

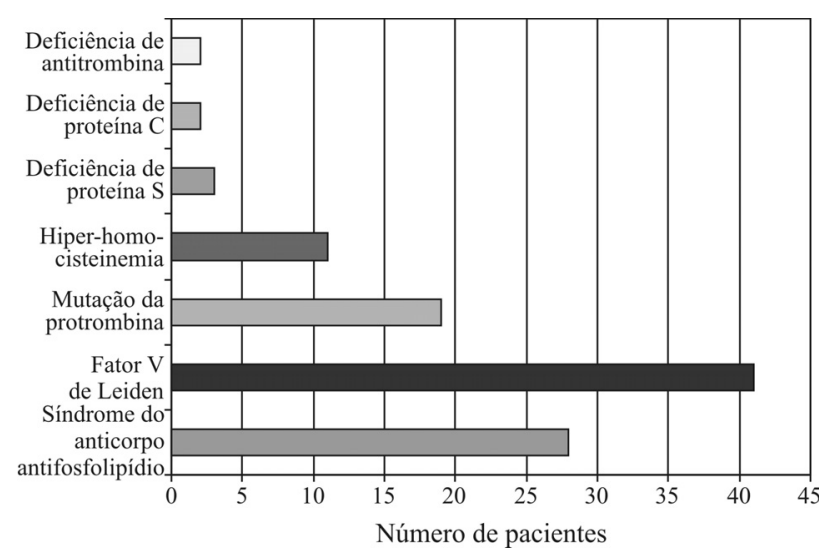

Figura 3 - Incidência dos tipos de trombofilias em eventos trombóticos venosos, $\mathrm{n}=97$ pacientes (108 alterações trombofílicas) anticorpo anticardiolipina predominou amplamente $(62,5 \%)$ sobre as demais alterações trombofílicas (Figura 4). Há que se destacar ainda a mutação da protrombina e a hiper-homocisteinemia, contribuindo, ambas as alterações, com porcentagens de acima de $10 \%$ na incidência de trombose em pacientes trombofílicos. Em 21 casos (25\%), registrou-se a existência de antecedente familial para trombofilia.

\section{Discussão}

A doença tromboembólica tem etiologia multifatorial, sendo resultado de uma complexa interação de fatores genéticos e ambientais e podendo acometer tanto o sistema arterial quanto o venoso ${ }^{15}$.

Neste estudo, foi detectada uma prevalência significativa de trombofilia em pacientes que apresentaram evento trombótico no sistema venoso ou no arterial, ou ainda, embora mais raramente, em ambos, sem que houvesse, de modo significativo, predominância numa faixa etária considerada jovem (abaixo de 40 anos). Dos 112 pacientes com positividade para marcadores de trombofilia, $67 \%$ tinham idade acima de 40 anos, e 25,89\% tinham mais de 60 anos. A literatura médica destaca que mais de 50\% dos pacientes que sofrem um evento trombótico têm um defeito, congênito ou adquirido, em uma proteína da coagulação ou da plaqueta gerador de um estado de hipercoagulabilidade e que pode levar à trombose, especialmente quando a isso se associam fatores extrínsecos ou condições clínicas predisponentes ${ }^{16}$.

O predomínio de anticorpos antifosfolipídios e do FVL como condições trombofílicas sobre as deficiências de inibidores da coagulação já foi devidamente comprova-

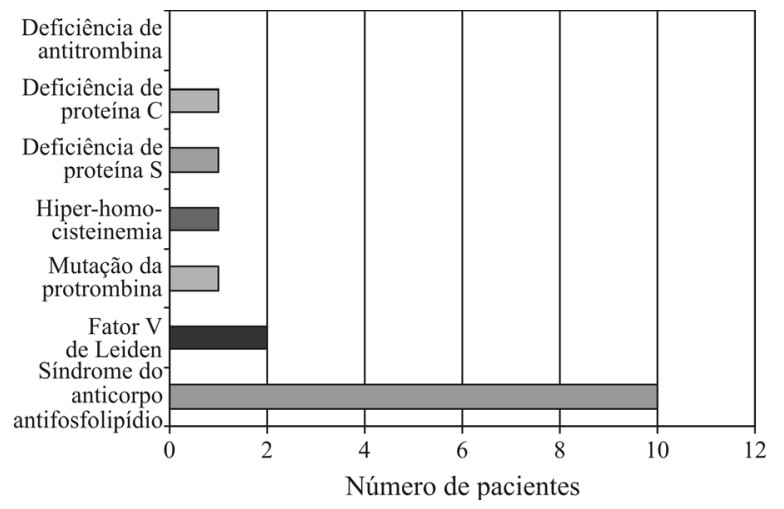

Figura 4 - Incidências dos tipos de trombofilia em eventos trombóticos arteriais, $\mathrm{n}=14$ pacientes (16 alterações trombofílicas) 
do em diversos trabalhos na literatura. A prevalência do FVL é de até $7 \%$ na população de origem branca ${ }^{6}$, e a de anticorpos antifosfolipídios pode chegar a mais de $20 \%$ em pacientes com TVP ${ }^{17}$, sendo a presença do anticorpo anticardiolipina cinco vezes mais comum do que a do anticoagulante lúpico $^{18}$.

A maior ocorrência da trombose no sistema venoso em casos de trombofilia, especialmente a TVP de membros inferiores, vem sendo constatada por diversos trabalhos epidemiológicos. De 30 a $50 \%$ dos pacientes com TVP têm defeitos congênitos de proteínas da coagulação, e cerca de $28 \%$ têm $\mathrm{SAF}^{17}$. Isto tem sido analisado sob a óptica de que o mecanismo de formação do trombo difere no sistema venoso e no território arterial. Enquanto que no primeiro predomina a trombose por alteração da cascata da coagulação, no segundo, a adesividade e a agregação plaquetária são o ponto de partida para a trombogênese. Como as alterações trombofílicas induzem mais alterações na cascata da coagulação do que na atividade plaquetária, é explicável, nos levantamentos sobre manifestações de trombofilia, o predomínio da trombose venosa em relação à trombose arterial. Como já foi referido acima, o evento trombótico mais comum é o que se instala no sistema venoso dos membros inferiores, mas é descrito também o acometimento em outros setores como as veias mesentéricas, renais, hepáticas, porta e cava ${ }^{19}$. Os eventos arteriais são mais raros nos defeitos das proteínas da coagulação; já na SAF, especialmente na presença primária do anticorpo anticardiolipina (sem uma comorbidade clínica subjacente), os eventos arteriais podem ser quase tão comuns quanto os venosos ${ }^{20}$, em contraposição à presença do anticoagulante lúpico primário na qual a manifestação mais frequente é a TVP ${ }^{18}$. Esta diferenciação esteve também presente na casuística analisada, na qual foram encontrados oito casos de manifestações de trombose arterial em pacientes com positividade para o anticorpo anticardiolipina contra apenas um caso em paciente com anticoagulante lúpico positivo.

O fato da recorrência da trombose acontecer em aproximadamente um terço dos pacientes diagnosticados com trombofilia e do antecedente familial de trombose ser registrado em mais de $25 \%$ dos casos analisados neste estudo, mostra a importância de se proceder sempre à profilaxia nos trombofílicos frente às situações de risco ${ }^{21}$, bem como a relevância de se identificar em cosanguíneos a alte- ração pró-trombótica para que eles também sejam objetos das mesmas medidas preventivas a fim de evitar os transtornos de uma coagulação anormal.

Uma investigação sistemática em casos de eventos trombóticos traria como vantagem um maior conhecimento da etiopatogenia e da agressividade destas trombofilias, o que permitiria tomar decisões mais embasadas quanto à duração do tratamento anticoagulante, à necessidade da pesquisa nos familiares ${ }^{22}$ (ascendentes e descendentes) e à profilaxia adequada para uma prevenção eficaz de eventos trombóticos, aumentando em muito as chances de redução da morbidade e da mortalidade que esses eventos trombóticos podem desencadear.

Os argumentos que poderiam contraindicar uma pesquisa regular de marcadores de trombofilias em eventos trombóticos seriam: a) o fato de que a doença tromboembólica tem etiologia multifatorial e de que a presença de marcadores de trombofilia não deve ser considerada como fator único na sua etiopatogenia, mas apenas um fator contribuinte; b) os testes laboratoriais de alguns desses marcadores de trombofilia carecem de padronização universal; e c) a pesquisa dos marcadores de trombofilia é dispendiosa, tanto para os sistemas públicos quanto para o privado de saúde, sendo que o seu custo-benefício ainda não foi determinado com precisão.

\section{Conclusão}

No presente estudo, a presença de marcadores de trombofilia, hereditários ou adquiridos, nos pacientes com eventos trombóticos, venosos e/ou arteriais, independentemente da localização, faixa etária ou existência de fatores extrínsecos associados, foi significativa.

\section{Referências}

1. Egeberg O. Inherited antithrombin deficiency causing thrombophilia. Thromb Diath Haemorrh. 1965;13:516-30.

2. Kottke-Marchant K, Duncan A. Antithrombin deficiency: issues in laboratory diagnosis. Arch Pathol Lab Med. 2002;126:1326-36.

3. Kottke-Marchant K, Comp P. Laboratory issues in diagnosing abnormalities of protein $\mathrm{C}$, thrombomodulin and endothelial cell protein $\mathrm{C}$ receptor. Arch Pathol Lab Med. 2002;126:1337-48.

4. Goodwin AJ, Rosendaal FR, Kottke-Marchant K, Bovill EG. A review of the technical, diagnostic, and epidemiologic considerations for protein S assays. Arch Pathol Lab Med. 2002;126:1349-66. 
5. Bick RL, Kaplan H. Syndromes of thrombosis and hypercoagulability. Congenital and acquired causes of thrombosis. Med Clin North Am. 1998;82:409-58.

6. Press RD, Bauer KA, Kujovich JL, Heit JA. Clinical utility of factor V Leiden (R506Q) testing for the diagnosis and management of thromboembolic disorders. Arch Pathol Lab Med. 2002;126:1304-18.

7. McGlennen RC, Key NS. Clinical and laboratory management of the prothrombin G20210A mutation. Arch Pathol Lab Med. 2002;126:1319-25.

8. Zivelin A, Mor-Cohen R, Kovalsky V, et al. Prothrombin 20210GA is an ancestral prothrombotic mutation that occured in whites approximately 24.000 years ago. Blood. 2006;107:4666-8.

9. Ho WK, Hankey GJ, Quinlan DJ, Eikelboom JW. Risk of recurrent venous thromboembolism in patients with common thrombophilia: a systematic review. Arch Intern Med. 2006;166:729-36.

10. Lonn E, Yusuf S, Arnold MJ, et al. Homocysteine lowering with folic acid and B vitamins in vascular disease. N Engl J Med. 2006;354:1567-77.

11. Cattaneo M. Hyperhomocysteinemia and venous thromboembolism. Semin Thromb Hemost. 2006;32:716-23.

12. Levine JS, Branch W, Rauch J. The antiphospholipid syndrome. N Engl J Med. 2002;346:752-63.

13. European Genetics Foundation; Cardiovascular Disease Educational and Research Trust; International Union of Angiology, et al. Thrombophilia and venous thromboembolism. International consensus statement. Guidelines according to scientific evidence. Int Angiol. 2005;24:1-26.
14. Miyakis S, Lockshin MD, Atsumi T, et al. International consensus statement on an update of the classification criteria for definite antiphospholipid syndrome (APS). J Thromb Haemost. 2006;4:295-306.

15. Franco RF. Trombofilias hereditárias. In: Maffei FH, editor. Doenças vasculares periféricas. Rio de Janeiro: MEDSI; 2002.

16. Bick RL, Kaplan H. Síndromes de trombose e hipercoagulabilidade. In: Bick RL. Trombose. Cl Med N Am. Rio de Janeiro: Interlivros; 1998.

17. Petri M. Epidemiology of the antiphospholipid antibody syndrome. J Autoimmun. 2000;15:145-51

18. Bick RL. Hereditary and acquired thrombophilic disorders. Clin Appl Thromb Hemost. 2006;12:125-35.

19. Van Cott EM, Laposata M, Prins MH. Laboratory evaluation of hypercoagulability with venous or arterial thrombosis: venous thromboembolism, myocardial infarction, stroke, and other conditions. Arch Pathol Lab Med. 2002;126:1281-95.

20. Bick RL. Antiphospholipid thrombosis syndromes: etiology, pathophysiology, diagnosis and management. Int J Hematol. 1997;65:193-213.

21. Paschôa AF. Impacto da pesquisa laboratorial de trombofilia na prevenção secundária e orientação dos doentes com tromboembolismo venoso. J Vasc Bras. 2006;5:331-2.

22. Simioni P. Who should be tested for thrombophilia? Curr Opin Hematol. 2006;13:337-43.

Correspondência:

Marcos Arêas Marques

Rua Sorocaba, 464/308, Bairro Botafogo

CEP 22271-110 - Rio de Janeiro, RJ

E-mail: mareas@centervasc.com.br 